\title{
Influence of freezing skin grapes to extract phenolic compounds during red wine maceration
}

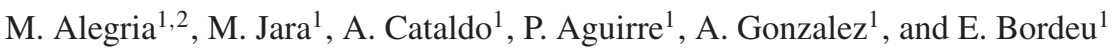 \\ ${ }^{1}$ Departement of Fruit Production and Enology, Faculty of Agronomy and Forestry Engineering, Pontificia Universidad \\ Católica de Chile, Santiago, Chile \\ ${ }^{2}$ Master International Vintage- École Supérieure d'Agriculture d'Angers, Angers, France
}

\begin{abstract}
Wine quality depends on phenolic and aromatic compounds that are mainly located in skins and seeds of grapes and can be better extracted if suitable extraction technologies are applied. An increase in extractability has impact in the mouth feel, color and age ability of the wines. Using liquid or solid $\mathrm{CO}_{2}$ is a way to promote the breakdown of the cells membranes and enhance extraction of these compounds and protecting grapes and wine from oxidation. The main goal was to test the impact of solid $\mathrm{CO}_{2}$ addition to destemmed grapes with a new $\mathrm{CO}_{2}$ dispenser equipment in order to freeze the berry skins and improve the phenolic extraction in an economic and sustainable way in cv. Cabernet Sauvignon and Pinot Noir. The experiment designed for both cultivars was a treatment with $\mathrm{CO}_{2}$ addition and a control without $\mathrm{CO}_{2}$ addition each one with three replicates. Destemmed grapes submitted to carbonic snow reached temperature of the skins between -1 and $-4{ }^{\circ} \mathrm{C}$ during four minutes under equipment treatment. The consumption of carbon dioxide was estimated around $0.3\left(\mathrm{~kg} \cdot \mathrm{kg}^{-1}\right) \mathrm{CO}_{2}$ per berries. Wines of Cabernet Sauvignon and Pinot noir from fresh grapes and frozen grapes were made and were being compared in phenolic composition and sensory attributes.
\end{abstract}

\section{Introduction}

Many of the compounds that give identity and quality to the wines are located in the skin of grapes. Processes of solid-liquid extraction transport these compounds from the skins to the juice, must or wine, prior, concurrent or after the alcoholic fermentation. In the current enological conditions, the extraction processes of these compounds are carried out in partial and limited way. This situation represents a space for innovation and a significant increase in the value of the production of wine. An increase in extractability of these compounds giving quality could mean an increase in several properties of the wine, such as color (anthocyanins), flavor (flavan-3-ols), aroma (varietal aromas), structure and texture in the mouth (proanthocyanidins) and nutritional quality, particularly its antioxidant and anticancer capacity. One technique unexplored is the supra-extraction which through partial freezing of the grapes, modify the structure of the skin at the cellular level, increasing the extractability of qualitative compounds. These techniques offer attractive advantages for the processing of dry and still wines. However, one of the major problems associated with the implementation of these techniques are the high operating costs, especially those related to cooling and freezing grapes, problem addressed in this project through the proposed use of new $\mathrm{CO}_{2}$ dispensers. Additionally, these new extraction techniques generate anaerobic conditions, preventing harmful oxidation and reduce cooling needs during harvest. Within the wine industry there is a high demand for new technologies (services or products) that allow raising the potential quality of the wine. This demand for the companies in the wine industry is based on a positioning strategy that pursues high-value wines, seeking a shift in the product image from an economic one with good value to a high quality wine (premium wines). The general objective of this study is to test a new method of freezing the skin of grapes using a new $\mathrm{CO}_{2}$ dispensing machine that will inject the $\mathrm{CO}_{2}$ to the destemmed grapes in order to freeze in a homogenous way with the minimal expense of carbon dioxide snow.

\section{Materials and methods}

\section{Material}

The grapes of Pinot noir were given by the winery Ventisquero of the harvest 2014 from the Leyda Valley, parcel 35. The harvest was manual and the transport of the grapes was in cases each one with $10 \mathrm{~kg}$ of average weight. The winery Undurraga provided the Cabernet Sauvignon grapes as well from the vintage 2014 from the Colchagua valley parcel C.19 sombra. Harvest as well by hand and each case had approximately $11,5 \mathrm{~kg}$. The $\mathrm{CO}_{2}$ dispenser equipment, "porta-cryo" and tanks were made and provided by Indura company.

\section{Methods}

The study consisted in two independent trials: one for Cabernet Sauvignon in Undurraga winery and another one 
with Pinot Noir in Ventisquero winery. Each trial was made at the moment of the traditional harvest time of the wineries for both cultivars: Pinot Noir 03- april-2014 and Cabernet Sauvignon on 24-april-2014. The experiment design for both cultivars was a treatment with $\mathrm{CO}_{2}$ addition (FT- Freezing treatment) and a control without $\mathrm{CO}_{2}$ addition (CT- Control treatment) each one with three repetitions. The grapes were destemmed, submitted to carbonic snow and taken to bins of $500 \mathrm{~kg}$ of capacity for the Pinot Noir cultivar and to stainless steel tanks made by Indura of $180 \mathrm{~kg}$ capacity for the Cabernet Sauvignon variety. The treatments were intercalated (CT and FT) to avoid subcooling of the machine. After fermentation, samples of 20/25 litters of each tank/bin were taken to the university to proceed with the malolactic fermentation, bottling, chemical and sensory analysis. During the trials several samples and measures were taken for posterior analysis: samples of frozen and not frozen berries after each treatment ( 5 in 5 minutes); measures of inlet/outlet temperatures of the skin of grapes using a thermocuple and infrared equipments before and after both treatments; time measurements: permanence of the berries in the machine and total time of each treatment; $\mathrm{CO}_{2}$ consumptions.

\subsection{Winemaking}

Bins were filled up with Pinot Noir grapes with a dosis of $90 \mathrm{gr} / 1000 \mathrm{Kg}$ of potassium metabisulphite was added and $40 \mathrm{gr} / 1000 \mathrm{~kg}$ of pectolitic enzymes. Must was macerated during 7 days with the care that all the bins had the same temperature using a cool equipment connected to the cold system of the winery to maintain the temperature around 10 degrees. The must was inoculated on the seventh day of maceration $(25 \mathrm{~g} / \mathrm{Hl})$. Measurements of temperature and densities were taken two times per day. During fermentation, the temperature was controlled using an equipment to increase the temperature to keep a constant temperature around $24-27^{\circ} \mathrm{C}$ degrees. Punch downs were made two times per day using a metallic instrument to help the operation. Tasting the musts was also a decision factor to know the frequency in the punch downs during the fermentation.

For the Cabernet sauvignon variety a dosis of $70 \mathrm{gr} / 1000 \mathrm{Kg}$ of potassium metabisulphite were added to the grapes initially. There was a maceration of 4 days with controlled temperature around $10^{\circ} \mathrm{C}$ using the cold system of the winery. On the 5th day, the tanks were inoculated with doses of $20 \mathrm{gr} / \mathrm{Hl}$. Densities and temperatures were taken two times per day. The pump-overs were made two times per day using buckets of $20 \mathrm{~L}$ and totally manually due to the small size of the tanks. In total, 7 buckets per tank were filled up and emptied on the top of the tank. To help with the manual pump-over, 4 times per week, nitrogen gas was used with a pressure of 20 bars. The tube of the gas was connected to the bottom valve of the tank and the nitrogen helped to move all the must and grapes pomace that normally got stuck in the wall of the tank due to the narrow format of the tank. After alcoholic fermentation, samples of $15 \mathrm{~L}$ were taken of each tank/bin of both cultivars to plastic containers to proceed with the malolactic fermentation at the laboratory of Enology at the Faculty of Agronomy and Forestry. After malolactic fermentation, the wines were sulphited and taken to the cold room for tartaric stabilization. After that, the wines were racked and bottled, correcting the free $\mathrm{SO}_{2}$.

\subsection{Enological parameters}

Basic analyses were done to the finished wines described by Bordeu and Scarpa (1998): pH by potentiometry; total acidity by potentiometry expressed as $\mathrm{g} / \mathrm{L}$ of $\mathrm{H}_{2} \mathrm{SO}_{4}$; alcohol content by aerometry; reductors sugars by Luff method; free $\mathrm{SO}_{2}$ by Ripper; volatile acidity by Blarez method.

\subsection{Colour and tannins measurements}

Several spectral analysis to red wine colour and phenolic measures were done to the finished wine following the protocols of Iland (2004): wine colour intensity, wine colour hue, degree of red pigment colouration, estimate of the concentration $\mathrm{SO}_{2}$ resistant pigments, total red pigments, total phenolics, modified wine colour density, modified wine colour hue, modified degree of red pigment colouration, modified estimate of the concentration $\mathrm{SO}_{2}$ resistant pigments. Tannins concentration was measured following the protocol of Dambergs et al., [1] by methylcellulose precipitable. Spectrophotometric absorbance readings were taken at 280,420 and $520 \mathrm{~nm}$ using cuvettes with a path length of $1 \mathrm{~mm}$.

\subsection{HPLC Analysis of Anthocyanins}

The standards used were: malvidine- 3-glucoside; delphini din-3-glucoside, ciannidin-3-glucoside and peonidin-3glucoside. The solutions were filtered with a PVDF membrane of $0,45 \mu \mathrm{m}$. The wines were filtered as well with a membrane of $0,45 \mu \mathrm{m}$. The column used was a Purospher START RP-18 endcapped (5 $\mu \mathrm{m}), 250 \mathrm{~mm}-4,6$. The mobile phase consisted of water with $5 \%$ formic acid (solvent A) and HPLC grade acetonitrile (solvent B). Chromatograms were recorded at $520 \mathrm{~nm}$. Anthocyanins were identified by their UV spectra and quantified as malvidin 3-glucoside.

\subsection{Statistical analysis}

For the all the chemical analysis and qualitative sensory analysis a statistical analysis of variance was done using one-way ANOVA with a confidential level of $95 \%$ using the Tukey method using the program Statgraphics Centurion XV.I.

For the paired comparison sensory evaluation, "two tailed" and "one tailed" statistical treatment was done according O’Mahony (1986).

\subsection{Sensorial analysis}

The sensorial analysis for Pinot Noir and Cabernet Sauvignon was done in a paired-comparative way, it means that 2 glasses were presented at each time in random way to each taster. In total there were 9 pairs with all the possible combinations between the control wines $(\mathrm{C} 1, \mathrm{C} 2$ 
and C3) and the ones with the freezing treatment (F1, F2 and F3). Comparing the pair of wines, the taster should choose which wine has more intensity in the descriptors chosen (artificial fruit, fresh fruit, cinnamon, dry herbs, volume, dryness and colour intensity for Pinot Noir and berries, mature dry fruit, volume and dryness for Cabernet Sauvignon). A panel of 10/12 experts tasted the wines.

\section{Results and discussion}

\section{Enological parameters}

FT wines of Pinot Noir presented statistical difference with lower titratable acidity, higher values of reductors sugars and volatile acidity. The high values of volatile acidity is explained by a contamination that was present in the winery. For the FT wines of Cabernet Sauvignon presented lower values of titratable acidity, high values of $\mathrm{pH}$ and high values of reductors sugars. The high values of reductors sugars in FT wines is explained by the tendency to have lower temperatures since the beginning and during the fermentation even if we try to keep a similar temperature between CT and FT wines. Freezing grapes can affect titratable acidity, tartaric acid, $\mathrm{pH}$ and potassium content and when initial juice or wine $\mathrm{pH}$ is above $\approx 3.65$, the precipitation of potassium bitartrate causes an increase in $\mathrm{pH}[2]$.

Table 1. Enological characteristics of the wines.

\begin{tabular}{|c|c|c|c|c|c|}
\hline & T.A & $\mathrm{pH}$ & A.C. & R.S. & V.A \\
\hline PN CT & $\begin{array}{l}4,1 \quad \mathrm{a} \\
(0,1)\end{array}$ & $\begin{array}{l}3,46 \text { a } \\
(0,06)\end{array}$ & $\begin{array}{l}14,9 \text { a } \\
(0,4)\end{array}$ & $\begin{array}{l}2,4 \quad a \\
(0,2)\end{array}$ & $\begin{array}{l}0,48 \text { a } \\
(0,02)\end{array}$ \\
\hline PN FT & $\begin{array}{l}3,9 \quad b \\
(0,2)\end{array}$ & $\begin{array}{l}3,46 \text { a } \\
(0,02)\end{array}$ & $\begin{array}{l}15,4 \text { a } \\
(0,5)\end{array}$ & $\begin{array}{l}2,68 \text { a } \\
(0,2)\end{array}$ & $\begin{array}{l}0,53 \mathrm{~b} \\
(0,01)\end{array}$ \\
\hline $\mathrm{CS} \mathrm{CT}$ & $\begin{array}{l}3,5 \quad a \\
(0,2)\end{array}$ & $\begin{array}{l}3,4 \quad \mathrm{a} \\
(0,03)\end{array}$ & $\begin{array}{l}12,9 \text { a } \\
(0,2)\end{array}$ & $\begin{array}{l}1,22 \mathrm{a} \\
(0,02)\end{array}$ & $\begin{array}{l}0,2 \text { a } \\
(0,0)\end{array}$ \\
\hline CS FT & $\begin{array}{l}3 \quad b \\
(0,1)\end{array}$ & $\begin{array}{l}3,5 \quad b \\
(0,03)\end{array}$ & $\begin{array}{l}13 \quad a \\
(0,3)\end{array}$ & $\begin{array}{l}1,15 \mathrm{~b} \\
(0,06)\end{array}$ & $\begin{array}{l}0,23 \text { a } \\
(0,1)\end{array}$ \\
\hline
\end{tabular}

Different letters within the same column indicate significant differences $(\mathrm{p}<0,05)$. T.A: titratable acidity; A.C: alcohol content; R.S.: reductors sugars; V.A.: Volatile acidity. Standard deviation is reported in parentheses.

\section{Colour, tannins measurements and HPLC analysis}

FT wines of Pinot Noir presented statistical difference with higher values of modified degree of red pigment colouration. Tannins and anthocyanins by HPLC didn't show statistically difference except for delphidine-3acetilglucoside but there's a tendency for high values in FT wines. Moreover, the concentration of the main anthocyanin malvidine-3-glucoside presented lower values in FT wines but without significant difference. FT wines of Cabernet Sauvignon had less modified wine colour hue and higher concentrations of tannins [3]. In another hand spectral measure for colour and anthocyanins by HPLC show lower values for the FT wines especially for the delphidine, cianidine and peonidine glucoside. The formation of a maximum colour of the wines in the middle of fermentation and their lost of colour once the fermentation finished is a known fact. The increase of the colour is related with the increase of copigmented anthocyans as well as the values of anthocyans polimerized but if there's rupture of the copigmented anthocyans the colour will decrease. The FT has more effect if the grapes are less mature which can explain the no significant results in both cultivars because they were harvest with optimum mature levels [4].

Table 2. Iland spectral results (absorbance units) and Tannins by MCP.

\begin{tabular}{|c|c|c|c|c|}
\hline & PN CT & \begin{tabular}{|l|} 
PN FT \\
\end{tabular} & CS CT & CS FT \\
\hline W.C.D & $\begin{array}{ll}4,99 & a \\
(1,3) & \end{array}$ & \begin{tabular}{|l|}
5,36 \\
$(0,4)$
\end{tabular} & $\begin{array}{ll}8,8 & a \\
(0,8) & \end{array}$ & $\begin{array}{ll}7,63 & \mathrm{a} \\
(0,7) & \end{array}$ \\
\hline M.W.C.D & $\begin{array}{l}7,44 \\
(1,1)\end{array}$ & \begin{tabular}{|ll}
7,86 & $a$ \\
$(0,05)$ &
\end{tabular} & $\begin{array}{ll}13,5 & \mathrm{a} \\
(1,4) & \end{array}$ & $\begin{array}{ll}12,8 & a \\
(1,2) & \end{array}$ \\
\hline W.C.H & $\begin{array}{ll}0,72 & a \\
(0,05) & \end{array}$ & \begin{tabular}{|ll}
0,73 & $a$ \\
$(0,01)$ & \\
\end{tabular} & \begin{tabular}{|ll}
0,56 & $\mathrm{a}$ \\
$(0,01)$
\end{tabular} & $\begin{array}{l}0,57 \quad \mathrm{a} \\
(0,02)\end{array}$ \\
\hline M.W.C.H & $\begin{array}{ll}0,55 & \mathrm{a} \\
(0,01) & \\
\end{array}$ & \begin{tabular}{|ll}
0,57 & $\mathrm{a}$ \\
$(0,02)$ & \\
\end{tabular} & $\begin{array}{|ll|}0,45 & \mathrm{a} \\
(0,1) & \\
\end{array}$ & $\begin{array}{ll}0,44 & b \\
(0,1) & \\
\end{array}$ \\
\hline D.R.C & $\begin{array}{l}23,9 \\
(6,6)\end{array}$ & \begin{tabular}{|l|}
28,7 \\
$(5,8)$
\end{tabular} & $\begin{array}{l}20,37 \text { a } \\
(0,99)\end{array}$ & $\begin{array}{l}17,92 \mathrm{~b} \\
(0,91)\end{array}$ \\
\hline M.D.R.C & $\begin{array}{l}37,6 \\
(0,6)\end{array}$ & $\begin{array}{l}42,2 \\
(2,7)\end{array}$ & \begin{tabular}{ll|}
33,1 & $\mathrm{a}$ \\
$(2,1)$ & \\
\end{tabular} & $\begin{array}{l}32,8 \quad a \\
(1,04)\end{array}$ \\
\hline E.SO ${ }_{2}$ R.P & $\begin{array}{ll}1,08 & a \\
(0,43) & \end{array}$ & \begin{tabular}{|ll}
1,14 & $a$ \\
$(0,13)$ & \\
\end{tabular} & $\begin{array}{l}2,15 \quad \mathrm{a} \\
(0,11)\end{array}$ & $\begin{array}{l}1,91 \quad b \\
(0,15)\end{array}$ \\
\hline M.E.SO $\mathrm{SO}_{2}$ RP. & $\begin{array}{ll}1,02 & a \\
(0,32) & \end{array}$ & \begin{tabular}{|ll}
1,21 & $a$ \\
$(0,12)$ &
\end{tabular} & \begin{tabular}{|l|}
$2,06 \quad \mathrm{a}$ \\
$(0,19)$
\end{tabular} & $\begin{array}{l}1,83 \quad \mathrm{a} \\
(0,18)\end{array}$ \\
\hline T.R.P & $\begin{array}{ll}12,2 & \mathrm{a} \\
(1,11) & \\
\end{array}$ & \begin{tabular}{|ll}
11,9 & a \\
$(0,44)$ & \\
\end{tabular} & $\begin{array}{|ll|}27,6 & \mathrm{a} \\
(1,3) & \\
\end{array}$ & $\begin{array}{ll}27,1 & \text { a } \\
(1,7) & \\
\end{array}$ \\
\hline T.P. & \begin{tabular}{|l|}
33,7 \\
$(3,1)$
\end{tabular} & \begin{tabular}{|l|}
30,7 \\
$(4,1)$
\end{tabular} & $\begin{array}{|ll|}42,2 & \mathrm{a} \\
(1,5) & \\
\end{array}$ & $\begin{array}{ll}40,5 & \mathrm{a} \\
(1,7) & \end{array}$ \\
\hline $\begin{array}{l}\text { Tannins } \\
\mathrm{mg} / \mathrm{L} \\
\text { epicatechin }\end{array}$ & $\begin{array}{l}2091,4 \quad a \\
(240)\end{array}$ & $\begin{array}{l}2105,3 \quad a \\
(540)\end{array}$ & $\begin{array}{ll}2072 & \mathrm{a} \\
(179) & \end{array}$ & $\begin{array}{ll}2370 & b \\
(85) & \end{array}$ \\
\hline
\end{tabular}

Different letters within the same column indicate significant differences ( $\mathrm{p}<0,05)$. WCD: wine colour density; MWCD; modified wine colour density; WCH: wine colour hue; MWCH: modified wine colour hue; DRC: degree of red pigment colouration; MDRC: modified degree of red pigment colouration; $\mathrm{ESO}_{2} \mathrm{RP}$ : Estimate of $\mathrm{SO}_{2}$ resistant pigments; $\mathrm{MESO}_{2} \mathrm{RP}$ : modified estimate of $\mathrm{SO}_{2}$ resistant pigments; TRP: total red pigments; TP: total phenolics. Standard deviation is reported in parentheses.

\section{Sensorial analysis}

Tasters perceived more volume, cinnamon aromas and colour intensity to FT wines of Pinot Noir. In Cabernet Sauvignon, FT wines had more volume in comparison with CT wines that tasters perceived drier. FT wines of Cabernet Sauvignon having more concentration of tannins will affect the sensory characteristics of the wines, especially the astringency quality that is obtained as a result of an increase in the proportion of skin proanthocyanidins [5].

\section{1. $\mathrm{CO}_{2}$ consumptions}

Destemmed grapes submitted to carbonic snow reached temperature of the skins between -1 and $-4{ }^{\circ} \mathrm{C}$ during four minutes of permanence in the equipment. The consumption of carbon dioxide was estimated around 
$0.3 \mathrm{~kg} \mathrm{CO} 2 / \mathrm{kg}$ berries. In Pinot Noir trials to achieve all the three repetitions under zero degrees ${ }^{\circ} \mathrm{C}$ were difficult leading that in the last repetition an inferior proportion of grapes were frozen. The trials in Cabernet Sauvignon lead to grapes frozen with constant temperatures during the average time of 3:22 $\mathrm{min}$.

\section{Conclusions}

The results obtained show that FT wines of Pinot Noir had lower titratable acidity, higher values of modified degree of red pigment colouration and high values for the delphinidine-3-acetilglucoside. Sensorial analysis showed that tasters perceived more volume, cinnamon aromas and colour intensity for FT wines. Concerning the FT wines of Cabernet Sauvignon, lower titratable acidity and modified wine colour hue, higher values of $\mathrm{pH}$ and tannins concentrations were obtainable. Tasters perceived more volume in the FT wines and felt CT wines drier. The supraextraction technique could be considered and interesting technique to obtain wines with low astringency perception. Further improvements need to be done in the next year of the project.

\section{References}

[1] R. Dambergs, P. Smith, M. Mercurio, I. Francis, M. Herderich, AWRI. (2002)

[2] R. Threlfall, G. Main, J. Morris, Australian Journal of Grape and Wine Research. 12, 167 (2006)

[3] K. Sacchi, L. Bisson, D. Adams, Am. J. Enol. Vitic. 56:3, 199 (2005)

[4] I. Álvarez, J. Aleixandre, M. García, V. Lizama, Analytica Chimica Acta. 563, 111 (2006)

[5] N. Valverde, E. Plaza, J. Roca, R. Muñoz, A. Ortín, J. Agric. Food Chem. 59, 5454 (2011) 